ISSN: $1130-3743$ - eISSN: 2386-5660

DOI: http://dx.doi.org/10.14201/teoredu302177199

\title{
«YO NO QUERÍA SER PROFESORA». UN EJEMPLO PRÁCTICO DEL MÉTODO BIOGRÁFICO-NARRATIVO
}

\author{
"I did not want to be a teacher". A practical example \\ of the biographical-narrative method
}

\section{"Je ne voulais pas être enseignante». Exemple pratique de la méthode biographique-narrative}

Javier Feliciano Arnaldo Vega RAMírez

Universidad Austral de Chile. Facultad de Filosofía y Humanidades. Isla Teja, s/n. Valdivia, Región de los Ríos, 5110566 Chile.javier.vega@uach.cl

Fecha de recepción: enero de 2018

Fecha de aceptación: marzo de 2018

RESUMEN

La investigación biográfico-narrativa es un tipo de investigación que ha tenido gran repercusión durante los últimos años, debido a la revalorización de las metodologías cualitativas. En el mundo de la Educación se ha revelado como una técnica muy útil para explorar fenómenos en profundidad, habiendo grandes exponentes en idioma español que profundizan en particular en el sujeto del profesor. En el presente artículo se ofrece un estudio teórico de sus principales fundamentos junto con la transcripción y análisis de una entrevista a una docente, que permite aportar nuevos conocimientos sobre esta técnica de investigación.

Palabras clave: investigación cualitativa; investigación biográfico-narrativa; profesorado. 


\section{SUMMARY}

Biographical-narrative research is a type of research that has had great repercussion during the last years, due to the revaluation of the qualitative methodologies. In the world of Education has proved to be a very useful technique to explore phenomena in depth, having great exponents in Spanish language, that delve into the subject of the teacher in particular. This article offers a theoretical study of its main foundations together with the transcription and analysis of an interview with a teacher, that allows to contribute new knowledge about this research technique.

Key words: qualitative research; biographical-narrative research; teachers.

\section{SOMMAIRE}

La recherche biographique-narrative est un type de recherche qui a eu une grande répercussion pendant les dernières années, en raison de la revalorisation des méthodologies qualitatives. Dans le monde de l'Enseignement, elle s'est révélée comme une technique très utile pour explorer des phénomènes en profondeur, en ayant de grands exposants dans la langue espagnole, qui se plongent particulièrement dans le sujet de l'enseignant. Cet article offre une étude théorique de ses fondements principaux avec la transcription et l'analyse d'un entretien avec une enseignante, cela permet d'apporter de nouvelles connaissances sur cette technique de recherche.

Mots clés: recherche qualitative; recherche biographique-narrative; enseignants.

\section{INTRODUCCIÓN}

La investigación biográfico-narrativa explora la utilización de la historia de vida narrada en extenso como una oportunidad para construir un discurso auténtico que exprese de forma directa las tensiones vividas por una persona en un determinado momento de su vida. Es una metodología de análisis de discursos, toda vez que permite comprender dimensiones múltiples (cognitivas, afectivas y activas) al mismo tiempo que una perspectiva propia de análisis, por ser una forma de acceder al conocimiento propio de la investigación situada (Porta, 2010). Esta particularidad constituye su riqueza, ya que permite aproximarse a la cuestión narrativa, instalada en la investigación social desde el denominado "Giro Hermenéutico» (Gadamer, 1998) como un recurso propio de un campo de investigación particular como es el mundo de la Educación. En el artículo que aquí presentamos ofrecemos los resultados de una investigación que tuvo como objetivo analizar la trayectoria docente de una profesora en su último año de ejercicio, utilizando como técnica la investigación biográfico-narrativa, de modo de visualizar tanto su utilidad como herramienta investigativa como el lugar del sujeto personal en cuanto que significante de un sujeto colectivo. Para esto se desarrollaron una serie 
de entrevistas, las que luego son analizadas, sistematizadas y narradas como un todo continuo. Ofrecemos, por tanto, los referentes teóricos, conceptuales y los análisis aplicados a la narración sistematizada de la autora/narradora junto con las conclusiones resultantes.

\section{REFERENTES CONCEPTUALES}

\subsection{La investigación biográfico-narrativa}

La investigación biográfico-narrativa ha tenido un desarroll reciente, pero de gran penetración en el mundo investigativo. Se reconoce como la primera investigación desarrollada desde la perspectiva biográfico-narrativa el libro The polish peasant in Europe and America (Thomas y Znaniecki, 1918), texto que utiliza un corpus documental amplio que supera lo que hasta entonces se venía realizando. En la línea de nuevas exploraciones propias de la Escuela de Sociología de la Universidad de Chicago (Azpurúa, 2005), los autores utilizan como elemento de análisis cartas, diarios de vida y documentos personales, que sirven como recreación completa y compleja de la vida de los inmigrantes polacos llegados a América y sus familias. Para analizar dichos materiales se utilizan técnicas sociológicas a través de las cuales se hace patente que las narraciones no constituirían solamente un recurso individual, sino también colectivo (Humich y Reyes, 2013). Este es un elemento distintivo de la perspectiva biográfico-narrativa, su capacidad para analizar productos individuales y significarlos activamente desde una dimensión múltiple. Esta particularidad se transforma en un detalle problemático respecto de la investigación cualitativa tradicional, ya que los criterios de "validez", "generalización» y "Confiabilidad" dejan de representarse como adecuaciones directas en atención a la verdad, sino que comienzan a constituirse como construcciones representacionales propias del proceso de investigación (Bolivar, 2012). La utilización de este método tiene su gran implementación entre los años 1920 y 1940, en que es desplazado por la preferencia hacia métodos cuantitativos y cualitativos experimentales, en que los datos se vuelven a objetivizar, retomando su uso en la década de 1960, cuando aparece la investigación etnográfica The children of Sanchez (Lewis, 1961), publicada posteriormente como Los hijos de Sánchez (Lewis, 1964) que impacta profundamente tanto positiva (su difusión es masiva e inspira una película y nuevas ediciones en el mundo anglosajón) como negativamente (notorio en la polémica que rodea su edición en español en México). En cualquier caso, este texto revela cómo la utilización de métodos biográficos puede aportar una visión renovada sobre la realidad que antes se había desaprovechado (Bertaux, 1999).

Desde entonces, y hasta ahora sin interrupciones, ha retomado su posición como método de investigación, en un proceso constante de definición y validación de su utilización. Esto hace que se insista en su carácter de método investigativo con definiciones particulares que hacen que los problemas que antes se le adjudicaban, sobre la calidad de la relación con la verdad o sobre la forma de tratar 
los materiales y la calidad de los mismos, vayan siendo resueltos cada vez mejor (Campos, Biot, Armenia, Centellas y Antelo, 2011). Al respecto, Bolívar (2012) plantea que:

La investigación biográfico-narrativa incluye, al menos, cuatro elementos: (a) Un narrador, que nos cuenta sus experiencias de vida; (b) Un intérprete o investigador, que interpela, colabora y "lee» estos relatos para elaborar un informe; (c) Textos, que recogen tanto lo que se ha narrado en el campo, como el informe posterior elaborado; y (d) Lectores, que van a leer las versiones publicadas de la investigación narrativa (p. 81).

La dinamicidad de la incorporación de estos factores hace que la noción de verdad no sea la tradicional noción de correspondencia entre el dato dado y el dato recibido, sino el de la comprensión del hecho, sin que esto signifique una alteración de la realidad. Misma situación ocurre con el concepto de autoría de la narración, por cuanto la duda se establece entre quién es el autor principal del texto: si el narrador original o el intérprete, que muchas veces hace la transliteración de un sonido expresado, enriquecido con la experiencia re-leída y consentida por el otro. Este problema se hace patente en diversas obras, como es Vida de un araucano (Munizaga, 1960), cuyo narrador, Lorenzo Aillapán, escribe gran parte de sus experiencias, las que luego son tomadas por el intérprete, Carlos Munizaga, en una construcción limpia y ordenada, lo que hace que la autoría sea compleja en cuanto a la asignación directa. El autor no es el narrador, pero tampoco lo puede ser el solo transcriptor. El texto tiene así un doble origen, un origen material formal y un origen inmaterial formal. Misma situación ocurre con el texto Una flor que renace: autobiografía de una dirigente mapuche (Mallón y Reuque, 2003), en donde Isolde Reuque, dirigente católica con activa vida política y pastoral de la región de la Araucanía, hace una narración continua de su vida que luego es tomada por Florencia Mallón y editada para su lectura como texto. En este caso, como solución al problema de la autoría, se recurre a la incorporación de ambas personas como autoras del texto.

La investigación narrativa abre nuevos horizontes a la comprensión de la realidad, dado que se toma la narración como material de trabajo no solo para efectos de análisis documentario, sino que se comprende como fuente principal de una realidad cuya aproximación puede ser posible solamente por la trasposición del dato hecho por el narrador y recibido por el intérprete. Lo que hace que la relevancia no recaiga solo en el dato en sí, sino en el trasfondo narrado, y en la persona del lector que se transforma, en un nuevo plano, en intérprete y neonarrador. Se asume, por tanto, la complejidad de las relaciones establecidas entre narrador, intérprete, lector haciendo del texto un relato a interpretar (interpretandum) a través de otro texto que es el intérprete (interpretans) y que ofrece el texto como producto (Bolivar, 2012).

Junto con el tema de la autoría surge otro elemento fundamental para comprender el carácter de este tipo de investigación, y es el de las definiciones conceptuales. Si bien se utiliza de forma general el concepto de "biografía», tenemos 
dificultades para definir claramente si hablamos de biografía, entendida como la narración de los datos de vida de un tercero, dado que el mismo es quien muchas veces es quien protagoniza el relato (como es el caso de Lorenzo Aillapán en el texto antes citado). Asimismo, el concepto de "autobiografía", dado al texto de Isolde Reuque, reviste también dificultades por la precisión de ser una narración sobre sí misma, pero construido en modo de entrevista (apareciendo nuevas mediaciones del texto).

\section{CUADRO 1}

\section{RELACIÓN DE LOS ELEMENTOS INVOLUCRADOS EN UNA INVESTIGACIÓN NARRATIVA}

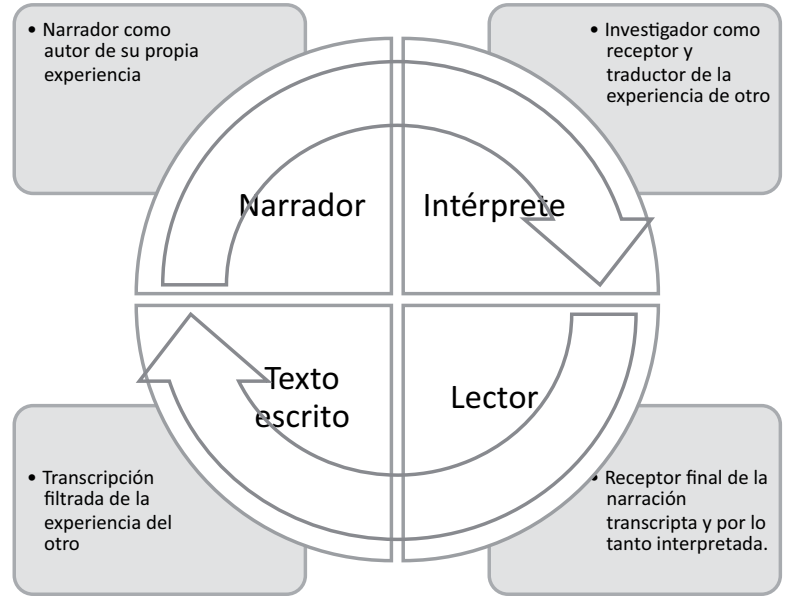

Fuente: Autor, basado en Bolívar (2012).

En el texto Los hijos de Sánchez de Lewis la dificultad viene dada por la combinación de diversas fuentes en un relato único que toma sentido según el interlocutor protagonista del relato (Bolivar y Domingo, 2006). Esto ha hecho que con el tiempo se requiera un consenso respecto de la terminología correcta a emplear para referirse al tipo de investigación según la extensión, posicionamiento y carácter del relato, distinguiéndose entre biografía, relatos e historias de vida.

En este sentido se acepta como clarificadora la distinción que hace Bertaux entre "Historias de Vida" y "Relatos de Vida» ${ }^{1}$, en donde la primera significaría la narración de un aspecto total y completo de la vida de una persona (hasta el punto

1. En inglés la diferencia resulta más natural al utilizarse los conceptos originales que distinguen entre relatos de vida (life stories) e historias de vida (life histories). 
en que esta vida está desarrollada), mientras que el segundo sería el relato de un extracto de esa vida, centrada en un momento particular, o en torno a un tema específico (Bertaux, 1999). Ambas serían biografías en el sentido que narran un evento particular de la vida de un sujeto, excluyendo el concepto de "autobiografía» en los casos en que un tercero intervenga en la mediación de la narración (Humich y Reyes, 2013).

\section{Metodología}

\subsection{Su utilización en Educación}

La particularidad del método es su utilización en la exploración de sentidos de personas particulares que representan a su vez a sujetos colectivos. La colectividad de la experiencia particular es lo que hace que el método sea utilizado como un registro etnográfico en particularidades culturales tales como lo son la identificación con un pueblo en particular, con un fenómeno determinante o con una historia relativa. Desde esta perspectiva la lógica del relato del Epónimo ${ }^{2}$ toma un carácter especial por no ser precisamente el protagonista del relato quien nombra el fenómeno, sino quien lo significa y simboliza a través de su narración, sea consciente o inconscientemente. Este elemento hace que el recurso narrativobiográfico tome especial interés en el mundo de la Educación por la pluriformidad de componentes que en él se encuentran. De hecho, la Educación se presenta en sí misma como un dónde particular, que se traduce en un contexto específico de desempeño y que configura identidades tanto particulares como colectivas toda vez que los discursos que genera constituyen un topos común de comprensión.

La investigación narrativo-biográfica aplicada a la Educación se trata, por tanto, de una forma de investigación que se basa en la experiencia personal configurada asimismo en la experiencia de otros (García, Lubián, y Moreno, 2011). De ahí que la aproximación posible, desde las perspectivas tradicionales de análisis, se muestra limitada por la irrupción del individuo como objeto de análisis, haciendo que el investigador se abra hacia los sujetos individuales en la construcción de un sí mismo que signifique a otros (Bolívar, 2002). La narración del sí mismo se constituye de esta forma en un discurso válido para la comprensión de la realidad no solo como un testimonio individual en subjetividad aislada, sino como registro desde una perspectiva de la historia personal que constituye, a su vez, una historia colectiva (Branda, 2014).

Dada esta amplitud es que la pregunta fundamental esté enfocada en dilucidar en primer término qué es educación o, mejor dicho, cuáles son los campos relativos que constituyen la experiencia denominada educación para luego ubicar

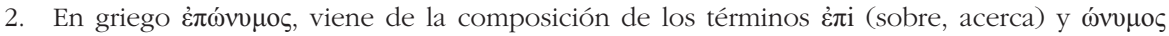
(nombre). El concepto se utiliza como identificador de un sujeto originante del nombre de algún lugar u objeto. 
al docente en relación a este amplio campo. Si hacemos una revisión de los principales autores que han estudiado este tema en Chile tenemos que la Educación se puede visualizar, siempre desde la noción de relación, en tres campos particulares: el campo de la relación estudiante-docente (en el conjunto de interacciones intra/ extraaula), el campo de la relación docente-sistema (entendiendo por sistema el conjunto de niveles relativos al ejercicio docente) y el campo de la relación estudiante/origen. Así tenemos que la cantidad de elementos que se pueden vincular en el ámbito de la Educación es múltiple y las posibilidades de explorarlos desde diversas perspectivas también lo es.

\section{CUADRO 2}

CONJUNTO DE RELACIONES POSIBLES EN EL CAMPO DE LA EDUCACIÓN

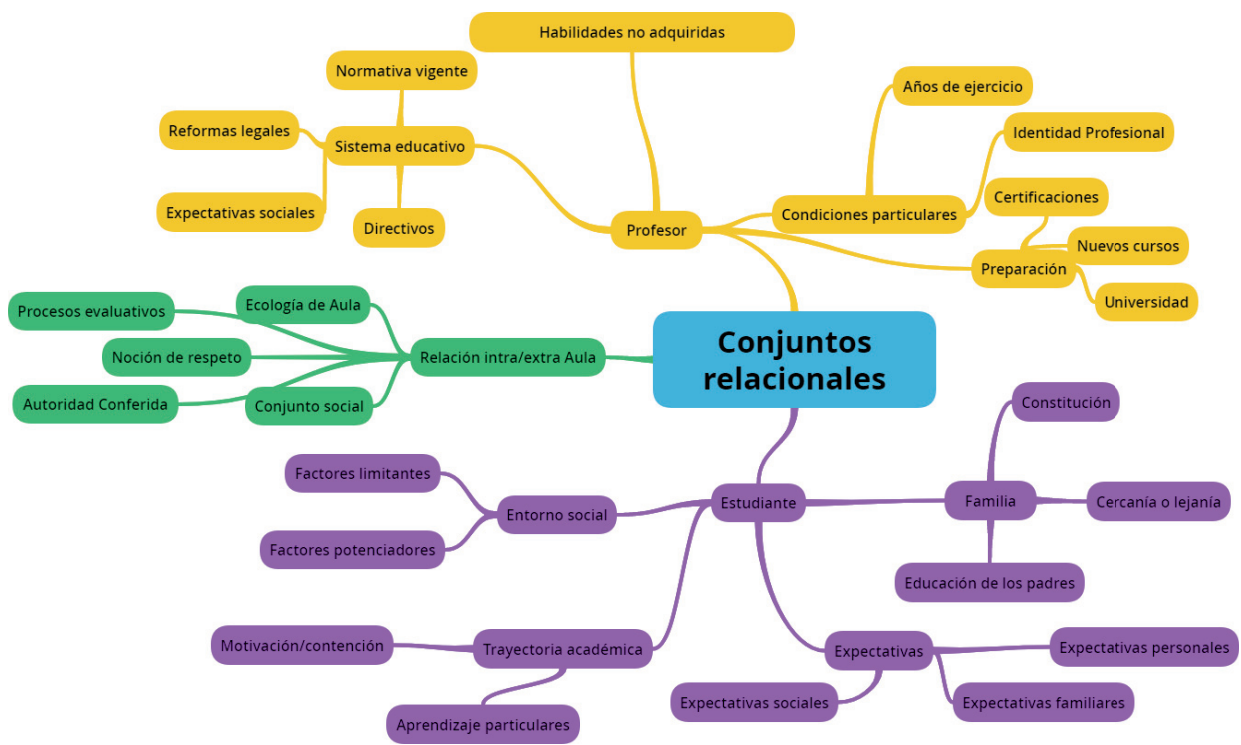

Fuente: Autor, basado en Brunner y Elaqua (2004); Cornejo y Redondo (2007); Marchesi, Lucena y Ferrer (2006); Cerón y Lara (2011); Irene y Bareño (2015); mineduc (2015); Vega y Galaz (2015).

La totalidad de estos conjuntos relacionales hace que los campos de investigación en Educación sean múltiples y variados y abran espacios para que se pueda investigar, desde el punto de vista de la investigación narrativa, con atención a diversos focos ${ }^{3}$.

3. La mayoría de las preguntas brotan de análisis de investigaciones actuales en Educación. Para mayores referencias consultar APple (1999); AEDO-Richmond (2000); BrunNER y ElaQua (2004); 
El desarrollo de investigaciones en torno a estas preguntas ha tenido tradicionalmente búsqueda de respuestas desde diversos ámbitos, centrándose particularmente en el caso chileno en análisis cuantitativos (niveles de influencia de factores de aprendizaje, relación de elementos posibilitantes o limitantes del aprendizaje) o análisis documentales e interpretativos de entrevistas y procesos de significación de experiencias (procesos de transformación ante la introducción de reformas, entre otros fenómenos), tenemos que el uso de investigaciones biográfico-narrativas ha desarrollado estudios sobre la experiencia del estudiante (Demazière y Dubar, 1997; Sparkes y Devís, 2001; Susinos y Calvo, 2005; Garza, 2013; Vásquez, 2013), pero, principalmente, ha centrado su uso en la narración de la experiencia de los docentes, poniendo especial énfasis en la manera en que ellos significan su experiencia de desempeño particular (Sarasa, 2011). En idioma español la numerosa producción de Bolívar (1998, 2001, 2002, 2003, 2004, 2004, 2005, 2006, 2008, 2011, 2012) ha abordado la experiencia de los docentes de España y otros lugares asumiendo la perspectiva biográfico-narrativa, permitiendo, a través de sus numerosas investigaciones, dar cuenta de las tensiones del desempeño docente, y de las relaciones que establecen los docentes en ejercicio, así como las tensiones curriculares, la vida de los centros educativos y el mundo de la educación en general (Humich y Reyes, 2013).

\subsection{La experiencia de vida docente}

Muchos son los investigadores que han profundizado en la posibilidad de tomar la educación como campo de investigación desde la investigación biográfico-narrativa, lo que hace que las posibilidades metodológicas y paradigmáticas sean diversas. Si bien la prevalencia de las investigaciones se centra en el tipo cualitativo en general, tanto los énfasis como los desarrollos se diferencian. Como bien lo plantea Goodson (1981), la evolución de las temáticas investigadas sobre los docentes ha evolucionado, pasando desde documentar su ser los «malos de la historia" en los procesos de exclusión y discriminación del alumnado de los años 60 , a ser las víctimas de un sistema opresor en los años 80, para convertirse en sujetos reales con vidas interesantes que ejercían la labor docente en el último período. En el texto "Professional Knowledge, Professional Lives: Studies of Education and Teaching» (Goodson, 2003) ${ }^{4}$, el mismo autor ofrece un extenso panorama de la diversidad de temáticas abordadas por diversos investigadores:

MARChesi, LuCENA y FERrer (2006); Cornejo y Redondo (2007); NúÑEz (2007); Bravo (2008); ACEVEDO y ROCHA (2011); CERÓN y LARA (2011).

4. En español, tenemos el artículo «Hacia un desarrollo de las historias personales y profesionales de los docentes", traducido del mismo texto, publicado por la Revista Mexicana de Investigación Educativa (2003). 
- Historias de vida y estudios biográficos (Goodson, 1981, 1992, 1995; Goodson y Walker, 1991; Tierney, 1998, 2000; Roberts, 2002).

- Generación de biografías colaborativas (Butt et al., 1992; Fine, 1994).

- Desarrollo profesional y micropolítico (Russell y Munby, 1992; Goodson y Cole, 1993; Goodson y Hargreaves, 1996).

- Otros trabajos de tipo feminista (Acker, 1989, 1994; Smith, 1990; Dehli, 1994; Munro, 1998).

- Desarrollo y envejecimiento docente (Thompson, 1988; Thompson et al., 1991; Plummer, 2001).

- Educación y desarrollo docente (Sikes, Measor y Woods, 1985; Goodson y Sikes, 2001; Ball y Goodson, 1985).

- Educación y dimensiones emocionales de su ejercicio (Hargreaves, 1998, 2001).

- Ejercicio docente y problemas asociados (Acker, 1989, 1999).

- Los docentes y la evolución económica (Robertson, 1994, 1996, 1997).

- Cómo se llega a ser docente (Bullough, 1989, 1998, 2000; Bullough et al., 1991).

Precisamente Bullough es quien sistematiza en el mundo anglosajón, con alta receptividad en el mundo de habla castellana, el proceso previo al ser docente, ubicando los estudios biográfico-narrativos desde la idea de ser docente hasta el ejercicio final de quien ejerce esta labor $(2000,131)$. Esto nos da cuenta de la amplia versatilidad de perspectivas posibles en el estudio del docente como sujeto de investigación desde el enfoque biográfico-narrativo, ya que no hay un punto único de partida. Como dice Clandinin (en Connelly y Clandinin, 2006) la investigación narrativa puede comenzar desde la historia o desde la narración de lo vivido entre las historias, dado que es un fenómeno en donde se debe adoptar una posición que en sí misma se hace experiencia 5 .

Actualmente, la investigación biográfico-narrativa en Educación desarrollada en español aborda alguno de los múltiples tópicos antes presentados. Siguiendo la revisión bibliográfica hecha por Humich y Reyes (2013), esta forma de investigar se ha desarrollado, entre otros países, en México, Brasil, Argentina y Chile con desiguales focos. Mientras en Brasil el objeto de estudio se centra en las trayectorias de vida de docentes, en México se diversifica la atención investigando Formación docente, Trayectoria docente (incorporación, formación y permanencia) y Profesionalización docente, mientras que en Argentina, cuya tradición en investigaciones biográfico-narrativas es mayor (Porta, 2010), iniciada particularmente por el trabajo del sociólogo Juan Francisco Marsal Hacer la América (1969), es continuada

5. La mayor parte de la producción de D. Jean CLANDinin (University of Alberta Canadá) está dedicada a la investigación narrativa. Ha abarcado otros aspectos de este tipo de investigación novedosos, tal como se ve en su última obra (colectiva) The relational ethics of narrative inquiry (Ed. Routledge, 2018), en colaboración con Vera CAINE y Sean LESSARD. 
en temas tan variados como Maestros inexpertos, Trayectoria y práctica profesional, Trayectoria de estudiantes, Trayectorias laborales, Experiencias pedagógicas. En el caso particular de Chile la investigación se ha centrado en historias de vida y trayectorias laborales (como es el caso de los ya citados trabajos de Munizaga y Reuque), profundizándose en esta perspectiva con ocasión de la apertura del nuevo campo de estudio que ha supuesto la investigación en Chile sobre Identidad Profesional, cuyos antecedentes los tenemos en el estudio de Gysling Profesores: un análisis de su identidad social (1992), y cuyo desarrollo se comienza a sistematizar posteriormente con diversos autores (Prieto, 2004; Núñez, 2004). Actualmente esta línea ha sido ampliamente trabajada por Alberto Galaz $(2011,2015)$ y Beatrice Ávalos (2012).

Siguiendo esta línea es que ofrecemos a continuación algunos párrafos extraídos del relato de vida de una docente del sur de Chile, profesora de Castellano y Filosofía, que estando en un período cercano a su jubilación realiza una revisión de lo que ha sido su trayectoria de vida desde que decide estudiar en la Educación Superior hasta el momento de la conversación. La narración permite transitar desde la inestabilidad docente propia del período final del Régimen Militar vivido en Chile entre 1973 y 1989 hasta la inestabilidad sobre la consideración a la imagen del docente, propia del sentimiento de los profesores en torno a las últimas regulaciones del trabajo del profesor, especialmente lo referido a la Carrera Docente ${ }^{6}$. Este relato permite sincerar la trayectoria profesional, pero al mismo tiempo la forma en que un docente logra instalarse en el mundo laboral desde la necesidad, muchas veces resuelta por el ingenio y la oportunidad.

Para destacar la utilidad de la investigación narrativa, se irán alternando los párrafos seleccionados con los análisis posibles de derivarse de su relación.

\section{Resultados}

\section{1. "Yo no quería ser profesora". Relato biográfico de una docente}

\subsubsection{Ser profesora}

[1] Yo llegué a estudiar a la Universidad Austral porque había quedado en lista de espera de Pedagogía en Inglés, pero yo no quería estudiar esto, sino que quería estudiar Idiomas, pero cuando di la Prueba de Actitud Académica puse varias opciones y postulé a varias universidades, pero el puntaje no me dio y quedé en la lista de espera de Pedagogía en Inglés en la

6. La discusión en torno a la Carrera Docente ha sido particularmente larga en Chile. La norma legal que la regula, la Ley 20.903 (MINEDUC, Ley 20.903, que crea el sistema de desarrollo profesional docente y modifica otras normas, 2016), fue aprobada en el Congreso posterior a una gran movilización y paro de los profesores en Chile que duró 57 días, entre el 1 de junio y el 27 de julio de 2015.

7. El relato, que se transcribe como un discurso continuo, corresponde a una serie de conversaciones, la principal en junio del año 2017. Para efectos de análisis posteriores posibles de efectuarse se presenta el texto separado en párrafos numerados por paréntesis cuadrados [ ]. 
Austral, y vinimos con una amiga para ver si corría la lista de espera. Yo era la segunda en la lista de espera, pero el jefe de carrera, de quien ya olvidé el nombre, me miró de arriba a abajo y me dijo que esperáramos un poco porque había corrido la lista y si no llegaba nadie más me podía inscribir. Yo como era de Chiloé y no sabía mucho alegar, porque una también era más pava ${ }^{8}$, me quedé ahí sentada mirando y esperando tres minutos y cuando iban a ser los tres minutos me acuerdo de que venía caminando una niña alta, bonita y algo desgarbada con un bolso atravesado y el jefe de carrera la saludó y ella se inscribió. Entonces quedé afuera, pero la amiga con la que había ido a estudiar me dijo que quedaban cupos en pedagogía en Castellano y Filosofía, así es que allá fuimos a inscribirnos. Y con eso ya estaba en la Universidad.

[2] La Universidad me la pagó una tía. Yo había terminado el Liceo en Chiloé y me había puesto en el negocio de un tío con una máquina de escribir, porque yo ya sabía escribir bien a máquina, pero los vecinos no sabían, así es que mientras mi tío arreglaba zapatos (porque para eso era su local) yo me dedicaba a escribirle las cartas o los documentos que los vecinos necesitaban a máquina y les cobraba según las páginas que escribía, porque había que hacer declaraciones, o cosas para el Seguro Social, y con eso pude juntar dinero para venirme a estudiar, pero no alcanzaba para pagar los estudios, así es que esta tía me vio con tanto entusiasmo y supo que me había ido bien en la prueba y me llamó y me dijo que ella me pagaría todos mis estudios, pero que estudiara algo que me sirviera, algo corto, algo que me ahorrara tiempo y plata. En ese tiempo había una carrera que se llamaba creo que Agente de Aduana, que era como un técnico, pero yo quería una carrera de cinco años. Y mi tía me aguantó, y con eso yo quedé contenta, feliz porque iba a poder estudiar, porque yo en esa época ya me creía el cuento que el estudio era la forma de asegurar la vida y yo me veía que iba a ser feliz y todo eso. Pero no sabía cómo eran las cosas porque luego me vine a estudiar y me tuve que matricular en pedagogía en Castellano y Filosofía, que no era lo que quería, porque yo no quería ser profesora, y lo pasé tan mal, estudié con mucho pesar, sufrí todo el tiempo de estudio, porque no estaba estudiando lo que yo quería, pero ni se me ocurría decir que no quería, porque en esa época era estudiar lo que se estudiaba no más y luego uno trabajaría y vería qué haría, así es que había que aguantar no más, además que todos decían que la Universidad era la clave del éxito, así es que desarrollé harta resiliencia y aprendí y estudié muchas cosas que no sabía para qué servían pero siempre pensando en terminar, pero no trabajar como profesora. Quería trabajar en lo que fuera, pero no ser profesora.

(análisis) Es destacable en la relación la insistencia en el estudio universitario como vía de transformación de la realidad. En este sentido el estudio y seguimiento de las trayectorias profesionales (tanto de Bullough como de Ávalos) dan cuenta de lo complejo y a veces errático proceso de selección e ingreso a la carrera profesional. En el caso de la autora/narradora, la selección de carrera va asociada a la discriminación y la sensación de disminución ante otra postulante (la expresión "yo como era de Chiloé» en el párrafo 1 es gráfica sobre la relación entre origen social y desarrollo de expectativas). La discriminación por aspecto físico, junto con

8. Distraída, sin capacidad para reaccionar. 
la arbitrariedad del jefe de carrera, se suman al sentimiento social del destino o la vida como determinante en su decurso autónomo.

A esta sensación se suma la noción fatal de que la elección no tenía otra alternativa que asumirse, en cuanto ser universitario y asociarse a una carrera es una elección sin alternativas. La verificación del sentimiento de no querer la carrera, junto con el hecho de perseverar en ella, obligan a revisar la comprensión de la continuidad en la labor docente como una opción dentro de la opción de estudios, para verificar que muchas veces el estatus de universitario es un logro en sí mismo y ser profesor es una profesión real. La expresión «estudié con mucho pesar, sufrí todo el tiempo» es una expresión que se invisibiliza continuamente, pero reaparece cada vez que en el relato se habla de la opción docente. Así, tomando la tipología del cuadro 2 (arriba), tenemos que la narración profundiza en el campo semántico del profesor en cuanto a su proceso personal, con el correlato de los trabajos de Hargreaves (1998, 2001), en el mundo anglosajón, y Galaz (2011), en Chile.

\subsubsection{El término de los estudios}

[3] Claro que en la Universidad estudié, y saqué la Carrera, pero no en el tiempo de los demás $[\ldots]$

[4] Pero era difícil vivir así, porque a veces no teníamos ni para la leche y mi familia estaba molesta conmigo y mi tía estaba molesta conmigo y no teníamos nada ${ }^{9}$. Al final pasaron varios meses y otra tía, que venía de Punta Arenas, vino a vernos a la pieza que arrendábamos y claro, una, pobre y todo, le ofrecí tecito y ella me quería mucho, pero me vio así, sin nada, y fue respetuosa, porque no preguntó mucho, se quedó varios días. Y cuando se iba a ir me dijo «mándale a tu tía (mi otra tía) un certificado que diga que eres egresada para que vea que por lo menos terminaste», y lo hice. Y mi tía me llamó, no sé cómo porque en ese tiempo había que ir a la Compañía ${ }^{10}$ y me dijo que me iba a ayudar. Y me envió dos giros de 14.000 pesos cada uno ${ }^{11}$, y con eso yo pude estudiar, buscar una niña que me cuidara mi guagua mientras tanto y dar mi examen de grado y eso hice. Así es que volví a Chiloé como profesora, pero no había trabajo como profesora, así es que mientras mi marido buscaba pololos por ahí yo busqué trabajo en el Mínimo ${ }^{12}$, y ahí estuve trabajando, hasta que nos enteramos que varios vecinos se habían ido a buscar trabajo a Argentina, porque en Argentina las cosas estaban mejores que en Chile.

9. En el párrafo 3, en extenso, la autora/narradora cuenta de cómo, en medio de sus estudios, se enamora, se casa y se embaraza, dejando sus estudios terminados, pero sin titulación.

10. Compañía de Teléfonos de Chile, en donde una operadora servía de enlace entre teléfonos.

11. El aporte final de dos giros de 14.000 pesos equivale a dos giros de 163.087 pesos actuales (203,31 dólares actuales cada giro).

12. Durante los últimos años del Gobierno Militar en Chile, y como una forma de paliar los índices de cesantía, se implementaron los programas PEM (Programa de Empleo Mínimo) y POJH (Programa de Ocupación para Jefes de Hogar), los que empleaban a trabajadores cesantes del país por bajos sueldos (SEPúlvedA, 2014). 
(análisis) El logro social de ser profesora no se condice finalmente con las condiciones reales para su ejercicio, lo que hace que al sufrimiento de no querer estudiar la carrera se suma el no tener cómo ejercerla. Aparece aquí un elemento característico de la época en que la autora/narradora estudia y finaliza su proceso (década de los 80) que es la dependencia de un tercero para lograr concretizar sus acciones. La ayuda de una tía, la colaboración de alguna vecina (para la conexión telefónica), la recepción del dinero, la contratación de una cuidadora para el hijo, dan cuenta de la creación y dependencia (aunque sea temporal) de otros que puedan colaborar en la concreción del proceso. El cierre del ciclo de estudios finaliza con el no encontrar trabajo, por lo que podemos secuenciar el proceso docente como: a) no estudiar la carrera que se desea, b) no desear la carrera que se estudia (pero que se asume), c) no lograr finalizar el proceso y d) (una vez finalizando) no lograr ejercer la carrera estudiada. La labor docente se configura entonces como una gran oposición emocional (Hargreaves, 1998) basado en factores sociales y ambientales (Robertson, 1997; Prieto, 2004). La migración se abre, así como un cierre y posible reapertura del proceso de ser profesor.

\subsubsection{Los primeros trabajos}

[7] Ella me preguntó que qué sabía hacer, que si buscaba trabajo y todo eso, y me contó que las chilenas podían trabajar como domésticas ${ }^{13}$ y que venían a veces las patronas a buscar empleadas así es que si yo quería ella me ayudaba a conseguir trabajo. Chuta, pensé yo, lo hago no más, aunque yo soy bien inútil para las cosas de la casa.

[10] Ahí estuve como un mes, hasta que por intermedio de otros chilenos pude saber dónde estaba mi marido. Claro que a Chiloé mandaba cartas contando que estaba todo bien, pero no sabía si estaría bien [...] No teníamos nada, pero por lo menos teníamos dos piezas y encontramos trabajo en una fábrica de fideos, que era mejor trabajo y en una fábrica conservera. Trabajaba ocho horas seguidas sin parar y nos pagaban nueve porque estaba prohibido sentarse porque si nos sentábamos llegaba la capataza y nos hacía pararnos. Yo terminaba el día tan adolorida, y apenas caminaba, era tanto el dolor que demoraba el triple de tiempo en llegar a mi casa.

[11] Como no tenía nada mejor que hacer iba a todas las actividades culturales que hacían: títeres, teatro, exposiciones, charlas, cursitos, y eso era admirable, porque ahí me sentía bien y comencé a conocer gente. Con el pasar de los meses una de las señoras que iba a las exposiciones me dijo que en el Colegio María Auxiliadora seguramente buscarían profesores.

(análisis) Este es, curiosamente, el único pasaje del relato completo en que, a pesar de la adversidad de las condiciones en que ejerce su labor la autora/narradora, no hay queja ni resistencia ante la realidad vivida. Hay dolor físico (párrafo 10), hay

13. Empleadas domésticas, temporales (por una función específica) o permanentes (puertas adentro) 
un proceso de estupor ante el trabajo desconocido (párrafo 7), hay incluso algo de desesperanza (párrafo 7), pero aun así se perciben expresiones de satisfacción que no están presentes en el resto del relato. La expresión «y eso era admirable, porque ahí me sentía bien y comencé a conocer gente» (párrafo 11) da cuenta de este hallazgo. El proceso laboral no docente, unido al entorno social cultural, se presentan como un escenario de satisfacción mayor que los demás escenarios vividos en la narración. Es, finalmente, la cultura adquirida, y el ambiente generado, lo que permitiría explicar la vinculación con el mundo de la docencia. Cuestión que se condice con muchos de los testimonios recogidos en varias investigaciones (particularmente importante es el trabajo de análisis de Galaz, 2011).

\subsubsection{El inicio de la labor docente}

$[12]^{14}$ Con eso ya podía decir que las cosas iban mejorando, ya estaba con mi marido y tenía trabajo. Y con el trabajo pasó lo que ya en la Universidad me había pasado, me esforcé pero no era lo que quería, y me preparé mucho, pero tenía el problema de la literatura argentina porque en la Universidad a lo mucho conocía a Borges y Martín Fierro, pero nada más, pero ahí tenía que darle libros a leer a las alumnas, y yo tenía que leerme los mismos libros, y me pasó varias veces que eran las 5 de la mañana cuando recién terminaba de leer los libros y a las 6 ya me estaba levantando y pensando en las preguntas de la prueba, porque las pruebas en ese tiempo eran así no más, una llegaba y dictaba las preguntas, y yo llegaba a las 7 a hacer clases y a tomar prueba y a revisar y a hacer todo lo que se necesitaba. Al mes ya tenía mi primer sueldo y con eso pudimos con mi marido arrendar un departamento y al siguiente mes pudimos viajar a Chiloé a buscar a mi hijo para llevarlo con nosotros.

(análisis) Nuevamente se vuelve en el relato hacia la resistencia, precisamente al comienzo del ejercicio docente. La expresión "me esforcé, pero no era lo que quería” (párrafo 12) es una vuelta a la narración inicial (párrafos 1-3) en donde ser profesora no era lo deseado ni lo buscado, por lo tanto, la asociación al ejercicio se vincula directamente. Esta es una particularidad de este tipo de estudio, el relato continuo y las variadas narraciones hacen que la realidad se plasme con total integridad, haciendo que lo no confesado muchas veces (el rechazo al ejercicio docente) aparezca tan evidente que puede llegar a identificar.

\subsubsection{La labor docente en Chile}

[14] A Chile volví en $1990^{15}$, pero no tenía trabajo, porque fui muy atarantada y tomé mis cosas y me vine y llegué donde mis papás [...] Lo pasé mal de nuevo porque no había en

14. El relato, en los párrafos omitidos, prosigue explicando cómo logra conseguir trabajo, aunque no como titular, sino bajo un arreglo "por ser extranjera" (párrafo 11).

15. El año 1990 se hace el traspaso del gobierno desde un régimen dictatorial hacia un régimen democrático, lo que se interpretó como el inicio de una era de prosperidad económica inmediata. 
qué trabajar. Un día íbamos pasando por una calle de Castro y mi hijito, que ya sabía leer, quedó mirando un papelito que estaba pegado en una ventana que ofrecía trabajo. Mi hijo lo leyó y me dijo "Mira mami, aquí tenemos trabajo", y yo miré y leí. Buscaban empleada puertas adentro y yo miré a mi hijo y me puse a llorar, porque puchas, la idea era avanzar y no retroceder y ya había trabajado como profesora, pero mi hijo estaba contento.

[15] De puro susto de volver a trabajar de empleada en una casa me vine a Valdivia a dejar Currículum [...] y no encontré trabajo, pero sí me encontré con un amigo de la Universidad que me dijo que estaban armando un proyecto educacional en Paillaco, en un colegio particular, en donde él sería director, y que no habían logrado encontrar un Inspector General. Yo le dije que no podía, porque tenía experiencia como profesora en Argentina, pero no como inspectora ni nada así es que no sabía mucho, pero él me dijo que para ser directivo lo importante no era saber mucho, sino saber mandar ${ }^{16}$.

[16] Y como era el único trabajo que me ofrecían, y yo necesitaba trabajar, acepté. [...] Ya después de 9 años el sostenedor vendió el colegio, y el nuevo dueño nos despidió a todos, así es que nos dejó sin trabajo ${ }^{17}$.

(análisis) El cambio de gobierno de Chile, pasando desde un gobierno militar a un gobierno democrático, fue interpretado por muchos de los chilenos que habían migrado voluntariamente, como una oportunidad de mejora de las condiciones sociales produciéndose una reintegración de chilenos desde otros países, lo que se suma al retorno de muchos chilenos exiliados. Sin embargo, las posibilidades de ambos grupos son dispares, ya que los chilenos exiliados migran con un trasfondo político que posteriormente se transforma en su respaldo, no así todos los migrantes voluntarios. Esta realidad está detrás de la poca fortuna de la autora/ narradora en la búsqueda de trabajo (párrafos 14 y 15), lo que curiosamente la coloca en posición directiva, ya que más allá de las competencias posteriormente adquiridas, su ingreso a un cargo de mayor responsabilidad en el sistema escolar se produce precisamente por no encontrar cupo en el sistema escolar. La relación de años en que ejerce y luego es despedida (año 1999) marca el inicio de la crisis del modelo economicista en la educación, en que varios colegios originados como empresas se vieron obligados a cerrar por su no rentabilidad. Este quiebre deja a los docentes sin redes de apoyo cesantes (párrafo 16). La vulnerabilidad ante

16. En el sistema educacional chileno los colegios particulares y particulares subvencionados por el Estado tienen libertad de nombramiento de los equipos directivos a discreción del sostenedor, encontrándose como normal legal lo dispuesto a la contratación por el Código del Trabajo. En el caso de los colegios municipales, el nombramiento tiene mayor relación con las competencias o concursos ganados, aunque la decisión final pasa por la discreción del alcalde como sostenedor. El nombramiento viene regulado por el Estatuto Docente (AG, 1991) y por el sistema de Alta Dirección Pública (MINEDUC, 2011).

17. Esto ocurre en el año 1999, en que en el sistema particular se podían vender los colegios como forma de obtener ganancias, siempre que se respetaran las leyes comerciales vigentes. En el caso de los docentes, al cambiar dueño del colegio, se les podía recontratar como si fuera un nuevo negocio o se les despedía por extinguirse la relación laboral formal. 
las variaciones económicas es un tema poco estudiado en Chile. En Argentina, en cambio, fue analizado por Ricardo Donaire (2012) desde la evolución económica y social, siguiendo la línea de Robertson (1997), aunque este último lo analiza desde la transformación del postfordismo.

\subsubsection{Obligaciones docentes}

[17] Como había conocido gente, y ya tenía experiencia, volví a buscar trabajo con el DAEM y con todos los colegios particulares, y encontré como profesora de Castellano en el Liceo Santa María la Blanca y en el Instituto María Auxiliadora, como todavía no se cambiaba a Jornada Escolar Completa ${ }^{18}$ tenía unas horas en un lugar y otras en otro, y alcanzaba a correr de un colegio a otro $[\ldots]$.

[18] Así estaba trabajando ya como profesora, acostumbrándome a hacer clases de Castellano, que ahora pasaba a llamarse Lenguaje y Comunicación, cuando concursé para tener horas titulare $^{19}$ de profesora en el Santa María La Blanca, y así dejar de ser profesora a contrata, y me gané las horas ${ }^{20}$ pero el director de ese tiempo me dijo que no me daría las horas de Lenguaje, sino que me daría las horas de Filosofía, y yo no quería, pero él dijo que no no más, así es que demandé al DAEM por no respetar mi concurso. Al final lo que se le ocurrió al director fue que me cambiara de Liceo, y que hiciera algunas horas de Lenguaje y algunas horas de Filosofía y de Ética, y yo me vine al Liceo en que estoy ahora, pero con horas de Ética y Filosofía, y tuve que volver a estudiar y aprender, y aprender no más, haciendo clases que yo no quería, pero había que hacerlo bien no más.

(análisis) Uno de los elementos que caracteriza la función docente en Chile es la volatilidad de los cargos. Si bien se tiene cierta estabilidad por los concursos públicos, la permanencia en un establecimiento no está asegurada, por la figura del sostenedor (el Municipio) como contratante ante múltiples establecimientos, lo que hace que un profesor pueda mantenerse «en sistema» pero cambiándose de colegios. En el caso de la profesora, en un nuevo inicio, el cambio implica también cambio de asignatura y sector de desempeño. Y nuevamente aparece el tono sombrío que caracteriza toda la denominación del ejercicio docente al indicar que "haciendo clases que yo no quería» (párrafo 18).

18. El cambio de jornada doble (clases en la mañana y en la tarde con cursos diferentes) a jornada escolar completa (clases de un solo curso continuo desde la mañana hasta media tarde) se comenzó a implementar en 1997, pero su consolidación se produce solo a partir del año 2000 (DESUC, 2005).

19. Un profesor en Chile puede tener horas "a contrata", lo que significa que puede ser despedido o renovado a voluntad del empleador cada 28 de febrero, o tener horas "titulares" que le pertenecen por haber ganado un concurso y que no pueden ser revocadas, salvo proceso administrativo.

20. Esto ocurre el año 2010. 


\subsubsection{La etapa final}

[19] Y desde entonces estoy trabajando acá. He visto pasar a varios directores, algunos mandaban, otros no hacían nada. Ahora el director dice lo que hay que hacer y uno no saca mucho con alegar, porque al final mandan no más, y no importa lo que uno diga, y la verdad es que yo ya estoy a un año de irme, por lo que ya no me importa nada, salvo cuando le faltan el respeto a un colega o se cometen injusticias, y todos hacen como que no importa, o ahora, cuando el gobierno nos pone el pie encima y aunque hagamos paro o marchas o lo que fuera no importa, porque no le importamos a nadie. Eso siento, que cada vez le importamos menos a nadie.

(análisis) El relato se hace evidentemente sombrío al poner en perspectiva la dificultad de localizar las coordenadas tradicionales del estudio como fuente de realización (advertibles tras los párrafos 1 y 3) con la realidad docente, en donde la arbitrariedad de las decisiones y las vicisitudes del cargo dan pie una significación sombría de la función docente. La frase que concluye los testimonios representa, tanto individual como colectivamente, el sentir de muchos docentes en el proceso de definición de su carrera y su vida, al establecerse la poca significación social del ejercicio y la profesión. Este elemento es interesante, particularmente por la conexión que hay con las primeras revisiones sobre la vida de los docentes en los años 60 (según la evolución propuesta por Goodson), en donde el docente es interpretado como el victimario, o el número dentro del conjunto. La expresión «no le importamos a nadie» (párrafo 18) resalta la complejidad de estar a las puertas de la jubilación, luego de una carrera y una profesión asumidas.

\section{CONCLUSIONES}

La utilización del método biográfico-narrativo en la comprensión y tratamiento de la información permite acceder a los datos de primera fuente, sin que la transcripción del relato deba ser literal, sino mediada por la interpretación del redactor de la narración el que, a través de las organizaciones temporales, la agrupación de secuencias temáticas y la complementación de recursos narrativos e históricos, permite dar cuenta de la realidad desde la visión del testigo directo sin que necesariamente se dude de la objetividad de texto presentado. En el texto aquí presentado el conjunto de narraciones testimoniales de la autora/narradora del relato se han organizado y editado en conjuntos temáticos que permiten ir construyendo una historia continua, pero, al mismo tiempo, fragmentada y reagrupada en torno a temáticas particulares. La organización temporal, real, da pie asimismo a una organización temática, intencionada, para comprender mejor la narración.

En el caso particular del mundo de la Educación, el seguimiento de las trayectorias docentes desde diversas perspectivas es una oportunidad para comprender de mejor manera todos los elementos que configuran este ambiente. La presentación de relato de una profesora en ejercicio que se acerca al final de su vida activa da sentido a la presentación sistemática que se hace en la primera parte de este 
artículo, para poder visualizar cómo un testimonio mediado permite comprender de mejor forma una profesión en un determinado punto de la historia.

De ahí que la lectura del relato presentado por la protagonista de la narración permite visualizar varios aspectos de la trayectoria laboral de una docente que, como reitera muchas veces, no desea ser profesora. Surgen como temas:

- La manera en que se elige la carrera docente.

- La inocencia y candidez con que se aceptan las injusticias, en este caso la del jefe de la primera carrera a la que pretende acceder.

- La dependencia económica de la familia para estudiar y la errática trayectoria que termina configurando permiten visualizar la inestabilidad que se desarrolla la actividad docente en Chile.

Algunos elementos que se vislumbran y que suelen pasar desapercibidas en fuentes oficiales brotan en la narración:

- El flujo migratorio de chilenos hacia Argentina en el período de la dictadura, como consecuencia de la crisis económica vivida en el país iniciada a inicios de la década de los 80 .

- La configuración de un discurso sobre la preponderancia del estudio universitario como medio de alcanzar la felicidad, discurso confirmado por la teoría económica imperante y que termina sustentando la transformación de la matriz productiva del país de cara a los años 90.

- La ilusión que supone la vuelta a la democracia en la combinación de discursos libertarios y de progreso, que contrasta a su vez con la incomprensible falta de oportunidades para un profesional (contradicción que se evidencia en la adopción de un discurso proestudios superiores y un desarrollo económico aún no logrado).

- La arbitrariedad con que se eligen los cargos directivos en el período suscrito, que se suma a las arbitrariedades con que los directores administran la educación.

- La insuficiente forma de resolver, por parte de la Universidad en los años 90, la demanda por la formación docente en tiempos de Reforma.

Todos estos elementos son temáticas que pueden y deberían ser profundizadas, toda vez que dan cuenta del desarrollo de la trayectoria de los docentes en un arco temporal comprendido entre los años 80 y hoy.

Así, el uso de la investigación biográfico-narrativa confirma su validez y extraordinaria utilidad para visibilizar realidades colectivas desde la visibilización de la experiencia individual, permitiendo iluminar cómo una vida individual, en este caso la vida de una docente de Chiloé en su trayectoria laboral, hace que se convierta en una voz colectiva que represente, sin ninguna intención performativa de hacerlo, la vida de los demás profesores. 


\section{REFERENCIAS BIBLIOGRÁFICAS}

Acevedo, C. y Rocha, F. (2011) Estilos de aprendizaje, género y rendimiento académico. Revista Estilos de Aprendizaje, 71-84.

AcKer, S. (ed.) (1989) Teachers, Gender and Careers. Londres, Falmer Press.

ACKER, S. (1994) Gendered Experience. Buckingham, Open University Press.

ACKER, S. (1999) The Realities of Teachers' Work. Londres, Cassell.

AEDo-Richmond, R. (2000) La educación privada en Chile: un estudio bistórico analítico desde el período colonial hasta 1990. Santiago de Chile, RIL Editores.

AG, C. d. (1991) Estatuto Docente. Santiago de Chile, Colegio de Profesores AG.

Apple, M. (1999) La política del saber oficial: ¡tiene sentido un currículum nacional? En vV. AA. Volver a pensar la Educación. Madrid, Morata, 409.

Ávalos, B. y Sotomayor, C. (2012) Cómo ven su identidad los docentes chilenos. Perspectiva Educacional, 77-95.

AzPurúa, F. (2005) La Escuela de Chicago. Sus aportes para la investigación en ciencias sociales. Sapiens. Revista Universitaria de Investigación, julio-diciembre, 25-35.

Ball, S. y Goodson, I (eds.) (1985) Teachers' Lives and Careers. Londres, Falmer Press.

BERTAuX, D. (1999) El enfoque biográfico: su validez metodológica, sus potencialidades. Proposiciones, 1-23.

Bolívar, A. (2001) La investigación biográfico-narrativa en educación. Enfoque y metodología. Madrid, La Muralla.

Bolívar, A. (2002) «¿De nobis ipsis silemus?»: Epistemología de la investigación biográficonarrativa en educación. Revista Electrónica de Investigación Educativa, 1-26.

Bolívar, A. (2003) La identidad profesional del profesorado: crisis y reconstrucción en tiempos de cambio, en Consejo escolar Castilla-La Mancha la profesión docente: situación actual y perspectivas. Castilla, Consejo Escolar Castilla-La Mancha, 72-104.

Bolívar, A. (2004) La educación secundaria obligatoria en España. En la búsqueda de una inestable identidad. REICE, Revista Iberoamericana sobre Calidad, Eficacia y Cambio en Educación, 1-22.

Bolívar, A. (2008) Historias de vida que deshacen profecías de fracaso. Cuadernos de Pedagogía, 56-59.

Bolívar, A. (2011) La recherche biographique narrative dans le développement et l'identité professionnelle des enseignants, en GONZÁLEZ, J. Entre formation, identité et mémoire: Les histoires de vie en Espagne. Paris, L'Harmattan, 59-96

Bolívar, A. (2012) Dimensiones epistemológicas y metodológicas de la investigación (auto) biográfica, en ABraHÃo, M. H. y PASSEGGI, M. C. Dimensões epistemológicas e metodológicas da investigação (auto)biográfica. Porto Alegre, Editoria da PUCRS, 79-109.

Bolívar, A. y Domingo, J. (2004) Competencias profesionales y crisis de identidad en el profesorado de Secundaria en España. Perspectiva Educacional, 11-36.

Bolívar, A. y DOMingo, J. (2006) La investigación biográfica y narrativa en Iberoamérica: Campos de desarrollo y estado actual. Forum Qualitative Sozialforschung/Forum: Qualitative Social Research, 1-33.

Bolívar, A.; Domingo, J. y FeRnández, M. (1998) La investigación biográfico-narrativa en educación. Guía para indagar en el campo. Granada, FORCE y Grupo Editorial Universitario.

Bolívar, A.; Fernández CruZ, M. y Molina, E. (2005) Investigar la identidad profesional del profesorado: Una triangulación secuencial. Forum Qualitative Sozialforschung/Forum: Qualitative Social Research, 1-26. 
BRANDA, S. (2014) La investigación biográfico-narrativa en Educación. Revista de Educación de la Facultad de Humanidades, 1-14.

BRAVO, D. (2008) La relación entre la evaluación docente y el rendimiento de los alumnos. Santiago de Chile, Centro de Microdatos de la Universidad de Chile.

Brunner, J. y Elaqua, G. (2004) Factores que inciden en una educación efectiva. Evidencia internacional. Revista Virtual La Educación, 139-140.

Bullough, R. (1989) First Year Teacher, A Case Stud. Nueva York, Teachers College Press.

Bullough, R. (1998) Musings on life writing, biography and case study in teacher education, en KRIDEL, C. (ed.) Writing Educational Biography, Explorations in Qualitative Research. Nueva York, Garland, 19-32.

Bullough, R. (2000) Convertirse en profesor, la persona y la localización social de la formación del profesorado, en BiddLe, B.; Good, T. y Goodson, I. (coords.) La enseñanza y los profesores. La profesión de enseñar, vol. 1. Barcelona, Paidós, 99-166.

Bullough, R.; KNOwles, G. y Crow, N. (1991) Emerging as a Teacher. Londres, Routledge.

BuTT, R.; RAYMOND, D.; MCCue, G. y YAMAGISHI, L. (1992) Collaborative autobiography and the teacher's voice, en Goodson, I. (ed.) Studying Teachers' Lives. Londres, Routledge, 51-98.

Campos, I.; Biot, M. J.; ARmenia, A.; Centellas, S. y ANTelo, F. (2011) Investigación Biográfico-Narrativa, parte 2. Apuntes de Curso.

CERón, F. y LARA, M. (2011) Factores asociados con el rendimiento escolar. Santiago de Chile, Ministerio de Educación.

Clandinin, J.; CAINe, V. y LessaRd, S. (2018) The relational ethics of narrative inquiry. Routledge, Canadá.

Clandinin, J. y Connelly, F. (2006) Narrative Inquiry, en Green, J.; CAmilli, G. y Elmore, P. (eds.) Handbook of complementary methods in education research. 3rd ed. Mahwah, NJ, Lawrence Erlbaum, 477-487.

CoRnejo, R. y REDONDO, J. (2007) Variables y factores asociados al aprendizaje escolar: una discusión desde la investigación actual. Revista Estudios Pedagógicos, 155-175.

Cox, C. y Gysuing, J. (1990) La formación del profesorado en Chile (1842-1987). Santiago de Chile, Editorial Popular.

Demazière, D. y Dubar, C. (1997) Analyser les entretiens biographiques. L'exemple de récits d'insertion. Paris, Nathan.

DeHLI, K. (1994) Subject to the new global economy: Power and positioning in Ontario labour market policy formation, en PRIEGERT, R. y GOODSON, I. (eds.) Rethinking Vocationalism: Whose work/life is it? Toronto, Our Schools/Ourselves, 113-141.

Desuc, D. (2005) Informe Final «Evaluación Jornada Escolar Completa». Santiago de Chile, Pontificia Universidad Católica de Chile.

DICOEX (2005) Chilenos en el exterior. Dónde viven, cuántos son y qué hacen los chilenos en el exterior. Santiago de Chile, DICOEX-INE.

DOnaIRE, R. (2012) Los docentes en el siglo XXI: ¿Empobrecidos o proletarizados? Buenos Aires, Siglo XXI.

Fine, M. (1994) Working the hyphens: Reinventing self and others in qualitative research, en Denzin, N. y Lincoln, Y. (eds.) Handbook of Qualitative Research. Londres, Sage, 70-82.

Foro Chileno por el Derecho a la Educación (2015) Análisis crítico de la Ley que regula la admisión de los y las estudiantes, elimina el financiamiento compartido y probíbe el lucro en establecimientos educacionales que reciben aportes del Estado. Santiago de Chile.

GadAmer, H. G. (1998) El giro Hermenéutico. Madrid, Ediciones Cátedra. 
GaLAZ, A. (2011) El profesor y su identidad profesional ¿facilitadores u obstáculos del cambio educativo? Revista Estudios Pedagógicos, 89-107.

Galaz, A. (2015) Evaluación e Identidad Profesional del profesor: ¿̨un juego de espejos rotos? Andamios, vol. 12, n. 27, 305-333.

García, M. R.; Lubián, P. y Moreno, A. (2011) La Investigación Biográfico Narrativa en Educación. Madrid, Universidad Autónoma de Madrid.

GarzA, N. (2013) Narrativas sobre la escuela preparatoria desde la perspectiva de los estudiantes, en $1 .{ }^{e r}$ Congreso Internacional de Investigación Educativa. Monterrey, Ediciones Universidad de Nueva León, 369-383.

Goodson, I. (1981) Life histories and the study of schooling. Interchange, 11 (4), 62-76.

Goodson, I. (ed.) (1992) Studying Teachers' Lives. Londres, Routledge.

Goodson, I. (1995) Teachers' life histories and studies of curriculum and schooling, en Goodson, I. (ed.) The Making of Curriculum: Collected Essays. 2. a edición. Londres, Falmer Press, 71-92.

Goodson, I. y Cole, A. (1993) Exploring the teacher's professional knowledge, en Mclaughiin, D. y Tierney, B. (eds.) Naming Silenced Lives. Londres, Routledge, 71-94.

Goodson, I. y Hargreaves, A. (eds.) (1996) Teachers' Professional Lives. Londres, Falmer Press.

GOOdSON, I. y SIKES, P. (2001) Life History Research in Educational Settings: Learning from Lives. Buckingham, Open University Press.

GoOdson, I. y WALKer, R. (1991) Biography, Identity and Schooling: Episodes in Educational Research. Londres, Falmer Press.

Gysling, J. (1992) Profesores: un análisis de su identidad social. Santiago de Chile, Centro de Investigación y Desarrollo de la Educación.

Hargreaves, A. (1998) The emotional practice of teaching. Teaching and Teacher Education, $14(8), 835-854$

Hargreaves, A. (2001) The emotional geographies of teaching. Teachers' College Record, 103 (6), 1056-1080.

Humich, D. y ReYes, R. (2013) La investigación biográfico-narrativa, una alternativa para el estudio de los docentes. Revista Electrónica "Actualidades Investigativas en Educación", $1-27$.

IRENE, M. y BAREÑO, T. (2015) Variables asociadas al desempeño escolar. Bogotá, Editorial Milla.

LEWIS, O. (1961) The children of Sanchez. New York, Penguin.

LEWIS, O. (1964) Los hijos de Sánchez. Ciudad de México, Fondo de Cultura Económica.

Mallón, F. y Reuque, R. (2003) Una flor que renace: autobiografía de una dirigente mapuche. Santiago de Chile, Centro de Investigaciones Diego Barros Arana.

MARCHESI, Á.; LucENA, R. y FERRER, R. (2006) La opinión de los alumos sobre la calidad de la Educación. Madrid, Fundación Hogar del Empleado.

Marsal, J. (1969) Hacer la América. Barcelona, Ariel.

MINEDUC (2011) Ley 20.541 de Calidad y Equidad en Educación. Santiago de Chile.

MINEDUC (2015) De inclusión escolar que regula la admisión de los y las estudiantes, elimina el financiamiento compartido y prohíbe el lucro en establecimientos educacionales que reciben aportes del Estado. Santiago de Chile, Gobierno de Chile.

MINEDUC (2016) Ley 20.903, que crea el sistema de desarrollo profesional docente y modifica otras normas. Chile. 
Munizaga, C. (1960) Vida de un araucano, El estudiante mapuche L. A. en Santiago de Chile en 1959. Santiago de Chile, Centro de Estudios Antropológicos de la Universidad de Chile.

Munro, P. (1998) Subject to Fiction: Women Teachers' Life History Narratives and the Cultural Politics of Resistance. Buckingham, Open University Press.

NúÑ́EZ, I. (2004) La Identidad de los docentes, una mirada histórica en Chile. Santiago de Chile, Programa Interdisciplinario de Investigaciones en Educación.

NúÑEZ, I. (2007) La profesión docente en Chile: Saberes e identidades en su historia. Revista Pensamiento Educativo, 41 (2), 149-164.

Plummer, K. (2001) Documents of Life 2: An Invitation to a Critical Humanism. 2. ${ }^{a}$ ed. Londres, Sage.

PORTA, L. (2010) La investigación biográfico narrativa en educación. Entrevista a Antonio Bolívar. Revista de Educación, 201-212.

Prieto, M. (2004) La construcción de la Identidad Profesional del Docente: un desafío permanente. Revista Enfoques Educacionales, 29-49.

RoBerTs, B. (2002) Biographical Research. Buckingham, Open University Press.

ROBERTSON, S. (1994) An exploratory analysis of post-Fordism and teachers' labour, en Kenway, J. (ed.) Economising Education: Post-Fordist Directions. Geelong, Deakin University Press, 105-152.

RoberTson, S. (1996) Teachers' work, restructuring and post-Fordism: Constructing the new professionalism, en Goodson, I. y Hargreaves, A. (eds.) Teachers' Professional Lives. Londres, Falmer Press, 28-55.

ROBERTSON, S. (1997) Restructuring teachers' labor: 'Troubling' postFordism, en BidDLe, B.; Good, T. y GoOdson, I. (eds.) International Handbook of Teachers and Teaching, 1. Londres, Kluwer, 621-670.

Russell, T. y MunBy, H. (1992) Teachers and Teaching from Classroom to Reflection. Londres, Falmer Press.

SARASA, M. C. (2011) La narrativa biográfica como vehículo para explorar las trazas de la buena enseñanza. Revista de Educación, 167-182.

SEPúlveda, M. (2014) Del trabajo protegido al trabajo subsidiado. Intervención, libre mercado y la situación de los trabajadores del PEM y POJH, 1974-1984, en I. d. UC, Seminario Simón Collier. Santiago de Chile, Pontificia Universidad Católica de Chile, 213-244.

Sikes, P.; Measor, L. y WoOds, P. (1985) Teachers' Careers: Crises and Continuities. Londres, Falmer Press.

SMiTH, D. (1990) Conceptual Practices of Power: A Feminist Sociology of Knowledge. Toronto, University of Toronto Press.

Sparkes, A. y Devís, J. (2001) La crisis de identidad de un estudiante universitario de educación física, un estudio biográfico, en Devís, J. La educación física, el deporte y la salud en el siglo XXI. España, Editorial Marfil, 87-100.

Susinos, T. y Calvo, A. (2005) "Yo no valgo para estudiar...», Análisis crítico de la narración de las experiencias de exclusión social. Revista Contextos Educativos, mayo 2013, $87-106$.

Thomas, W. y Znaniecki, F. (1918) The polish peasant in Europe and America. New York, Dover Publications.

Thompson, P. (1988) The Voices of the Past: Oral History. 2. ${ }^{a}$ ed. Oxford, Oxford University Press. 
"YO NO QUERÍA SER PROFESORA». UN EJEMPLO PRÁCTICO DEL MÉTODO BIOGRÁFICO-NARRATIVO

Thompson, P.; ITZin, C. y Abendstern, M. (1991) I Don't Feel Old: The Experience of Later Life. 2. ${ }^{\text {a }}$ ed. Oxford, Oxford University Press.

TIERNEY, W. (1998) Life history's history: Subjects foretold. Qualitative Inquiry, 4 (1), 49-70. TiERnEY, W. (2000) Undaunted courage: Life history and the postmodern challenge, en DENZIN, N. y Lincoln, Y. (eds.) Handbook of Qualitative Research. 2. ${ }^{a}$ ed. Thousand Oaks, CA, Sage, 537-554.

VÁsquez, L. (2013) «Un cuento donde yo no decidí qué escribirn: Narrativas de niñas y el sentido de su educación escolar. Tesis de grado para optar al título de Magíster en Estudios Humanísticos. Medellín, Universidad EAFIT.

VEGA, J. y GALAZ, A. (2015) Evidencias para una transformación y complejización del modelo chileno de evaluación docente. Educacão e Pesquisa, 171-183. 
